\title{
Toward a microRNA Signature of Endometrial Cancer
}

\author{
Eric J. Devor, Ph.D., ${ }^{1}$ Michael J. Goodheart, M.D., ${ }^{1,2}$ and Kimberly K. Leslie, M.D. ${ }^{1,2}$
}

Key Words: microRNA, endometrial cancer

\begin{abstract}
A simple meta-analysis of the eight surveys of microRNA (miRNA) expression in endometrial cancers reveals a panel of sixteen miRNAs that are significantly over-expressed $(n=15)$ or under-expressed $(n=1)$ in at least three surveys. Examination of these miRNAs indicates that they target mRNAs involved in a number of basic cellular processes including the crucial epithelial to mesenchymal transition (EMT) and hypoxia response. The central role played by these miRNAs is reinforced by the demonstration that they are all members of some of the most ancient of all animal miRNA families. This suggests that they may be part of a core set of miRNAs dysregulated as part of the carcinogenic cellular reprogramming process.
\end{abstract}

${ }^{1}$ The Department of Obstetrics and Gynecology, The Carver College of Medicine, The University of lowa, lowa City, lowa, USA

${ }^{2}$ Holden Comprehensive Cancer Center, The Carver College of Medicine, The University of lowa, lowa City, lowa, USA

\section{Introduction}

MicroRNAs (miRNAs) are 22nt long non-coding RNAs that, since their initial discovery nearly two decades ago, have been found to be ubiquitously involved in cellular processes throughout the plant and animal kingdoms ${ }^{1}$. MiRNAs act to regulate gene expression at both the transcriptional and posttranscriptional level thereby influencing hundreds of normal cell functions ${ }^{1}$. Further, dysregulation of miRNAs has been shown to play a role in dozens of human diseases, including cancers ${ }^{2}$.

We recently reported on an extensive survey of dysregulation of miRNA expression in endometrial endometrioid adenocarcinomas and endometrial serous adenocarcinomas ${ }^{3}$ and have followed that with a just completed survey of miRNA dysregulation in uterine carcinosarcomas ${ }^{4}$. Our two surveys bring to eight the total number of extant studies of miRNA dysregulation in endometrial cancers ${ }^{3-10}$. These surveys were carried out on a wide range of sample sizes, utilized different methodologies, and included a spectrum of endometrial cancer types, yet the compilation of results presented here reveals a core set of sixteen miRNAs whose expression was found to be significantly dysregulated in three or more of the studies. Examination of these miRNAs reveals that they affect

Please cite this paper as: Devor EJ, Goodheart MJ, Leslie KK. Towards a microRNA signature of endometrial cancer. Proc Obstet Gynecol. 2011 July;2(1):Article[7 p]. Available from: http://ir.uiowa.edu/pog/. Free full text article.

Corresponding author: Eric J. Devor, Ph.D. Department of Obstetrics and Gynecology, University of lowa Carver College of Medicine, 3234 MERF, 200 Hawkins Drive, lowa City, IA 52242. Telephone (319)3358212.eric-devor@uiowa.edu

This is an Open Access article distributed under the terms of the Creative Commons Attribution 3.0 Unported License (http://creativecommons.org/licenses/by/3.0), which permits unrestricted use, distribution, and reproduction in any medium, provided the original work is properly cited. 1 
central cellular processes and are, as a group, all members of evolutionarily old miRNA families. Thus, these commonly dysregulated miRNAs represent the first true candidates forming a core panel that, with further study, comprise a miRNA signature of endometrial cancer and, perhaps, other cancers as well.

Table 1. Characteristics of the eight extant miRNA surveys

\begin{tabular}{lllc}
\multicolumn{1}{c}{ Survey (Ref) } & \multicolumn{1}{c}{ Samples $^{1}$} & Method $^{2}$ & miRNAs \\
\hline Boren et al. (5) & 20BE, 37EEA, 4hyperplasia & Hybridization array & 335 \\
Chung et al. (6) & 38EEA, 26BE & miR-specific qPCR & 157 \\
Wu et al. (7) & 10EEC and NAT & Hybridization array & nd \\
Hiroki et al. (8) & 21ESA, 7BE & Hybridization array & 470 \\
Ratner et al. (9) & 5BE, 11EEA, 6ESA, 6UCS & TLDA (A-set Only) & 384 \\
Cohn et al. (10) & 141EEA, number of controls & Hybridization array & 326 \\
& not given & & \\
Devor et al. (3) & 4EEA, 4ESA, 4BE & TLDA (A-set and B-set) & 667 \\
Devor et al. (4) & 8UCS, 5BE & TLDA (A-set and B-set) & 667 \\
\hline
\end{tabular}

${ }^{1} \mathrm{BE}$, benign endometrium; EEA, endometrial endometrioid adenocarcinoma; ESA, endometrial serous adenocarcinoma; UCS, uterine carcinosarcoma; NAT, normal adjacent tissue

${ }^{2}$ Hybridization arrays are from various sources: Invitrogen NCode (Boren et al.), Microarrays Inc. (Wu et al.), Agilent (Hiroki et al.), Ohio State University Comprehensive Cancer Center miRNA chip v.3 (Cohn et al.) ; miR-specific qPCR primer-probe sets from Life Technologies; TLDA, Life Technologies qPCRbased Taq-Man Low Density Array (A-set $=384$ miRNAs, B-set $=283$ miRNAs)

${ }^{3} \mathrm{Wu}$ et al. do not provide the total number of miRNAs surveyed.

\section{Extant miRNA Surveys of Endometrial Cancers}

To date, there have been eight surveys of miRNA expression in endometrial cancers of which seven have been published and the eighth is in preparation ${ }^{3-10}$. The general characteristics of these miRNA surveys are presented in Table 1. As noted, the sample sizes and representation of both benign endometrium controls and the endometrial tumors types vary widely from study to study. Further, these studies surveyed a varied and only partially overlapping minority of the so far known total of 1,424 human miRNAs (miRBase Release 17, April 2011). Whatever the variation in sample size, tumor composition, and miRNA coverage may be, however, the techniques for determining miRNA expression levels are limited. In fact, there are but two methods available. 
One, the hybridization array, involves fluorescently labeling DNA fragments generated by reverse-transcription (RT) and hybridizing them to grids spotted with synthetic oligonucleotides composed of reverse complement (antisense) miRNA sequences. The fluorescence intensity of each position in the array is then measured and analyzed relative to known standards. The alternative technology, also based upon reverse transcription of cellular RNA, involves quantitative PCR (qPCR) of RT-generated cDNA fragments using primers and fluorescently labeled probes (TaqMan assays) specific to individual miRNAs. These assays are also normalized to endogenous RNA standards for subsequent expression analyses.

Taken together, the eight miRNA surveys overlap by, perhaps, only a few dozen miRNAs and yet a panel of sixteen miRNAs are found to be significantly dysregulated in endometrial cancers relative to benign endometrium in at least three of the eight surveys (Table 2). Moreover, half of these sixteen are found to be significantly dysregulated in endometrial cancers relative to benign endometrium in at least four of the eight surveys and two, $m i R-210$ and $m i R-205$, are found in six of eight and seven of eight surveys respectively.

\section{Discussion}

MiRNAs function to both preserve the overall homeostatic regulation of cellular processes and participate in normal cellular state transitions. Several miRNAs can target the same mRNA message and each miRNA can have multiple targets. This establishes networks of gene regulation involving both feed-back and feed-forward loops. Thus, when dysregulated, miRNAs can potentially be extremely disruptive. In cancers, miRNAs have been seen to be both significantly over-expressed and significantly under-expressed relative to benign tissues and to function as tumor suppressors or oncogenes depending upon the tumor type and tissue of origin $^{11,12}$. However, it is reasonable to expect that any particular miRNA will function consistently within the same cancer type. The sixteen miRNAs presented here are not only consistently either over- or under-expressed but can be expected to be carrying out the same pathogenic role in endometrial cancers regardless of histologic type. Proof of this principle is the presence of the entire miR-200 family of miRNAs in Table 2. This family, which emerged in eumetazoan genomes more than 500 million years $\mathrm{ago}^{13}$, is composed of five miRNAs in two polycistrons, miR-200c and miR-141 on chromosome 12 and $m i R-200 a$, miR-200b and miR-429 on chromosome 1 . Members of this family are well known to be crucially involved in epithelial to mesenchymal transition (EMT) in uterine and other tissues ${ }^{14}$ and miR-200c has been shown to regulate E-cadherin through the transcription factors ZEB1 and ZEB2 ${ }^{15}$. Coordinately regulated with the miR-200 family, miR205 , the most consistently overexpressed miRNA in these studies, also plays a key role in EMT through targeting ZEB1 and SIP1 ${ }^{16}$. A miRNA study of EMT in uterine carcinosarcomas (UCSs) determined that expression of miR-200 family members are significantly different in the epithelial component of UCSs versus 
the mesenchymal component with the former many-fold higher than the latter ${ }^{17}$. Dysregulation of miRNAs involved in EMT in endometrial cancers is consistent with the central role of EMT in both development and cancer ${ }^{18}$.

Another miRNA from Table 2 prominently represented in UCS EMT is
miR-155, seen to be nearly 80 -fold more highly expressed in the mesenchymal component than in the epithelial component ${ }^{17}$. This miRNA is linked to inflammation and has repeatedly been observed to be over-expressed in both hematologic cancers and solid tumors ${ }^{19}$.

Table 2. microRNAs significantly under- or over-expressed in endometrial cancers compared with benign endometrium in three or more of the eight extant surveys of miRNA expression in endometrial cancers.

microRNA Number of Studies References

Under -expressed:

miR-133 $\quad 4$ of $8 \quad[3,4,8,9]$

Over-expressed:

$\begin{array}{lll}\text { miR-205 } & 7 \text { of } 8 & {[3,4,5,6,7,8,9,10]} \\ \text { miR-210 } & 6 \text { of } 8 & {[3,4,5,6,7,8]} \\ \text { miR-200a } & 5 \text { of } 8 & {[3,6,7,8,9]} \\ \text { miR-200c } & 5 \text { of } 8 & {[3,6,7,8,10]} \\ \text { miR-107 } & 4 \text { of } 8 & {[3,4,5,6]} \\ \text { miR-203 } & 4 \text { of } 8 & {[6,7,8,10]} \\ \text { miR-182 } & 4 \text { of } 8 & {[6,7,8,9]} \\ \text { miR-10a } & 3 \text { of } 8 & {[6,7,8]} \\ \text { miR-31 } & 3 \text { of } 8 & {[3,7,8]} \\ \text { miR-106a } & 3 \text { of } 8 & {[5,6,8]} \\ \text { miR-141 } & 3 \text { of } 8 & {[3,6,7]} \\ \text { miR-155 } & 3 \text { of } 8 & {[3,6,7]} \\ \text { miR-183 } & 3 \text { of } 8 & {[3,6,8]} \\ \text { miR-200b } & 3 \text { of } 8 & {[3,7,8]} \\ \text { miR-429 } & 3 \text { of } 8 & {[3,7,8]}\end{array}$

Observed to be significantly overexpressed in six of the eight miRNA surveys, miR-210 offers a very straightforward example as well. Numerous studies of the relationship between hypoxia and miRNA expression have shown that miR-210 is the most hypoxia-responsive miRNA, intimately linked to the hypoxia-inducible factor Hif $1 \alpha^{20}$. Moreover, numerous miR-210 mRNA targets involved in cell cycle (PLK1, E2F3) and DNA repair (BLM), among others, have been experimentally validated. Similarly straight-forward is the one miRNA in Table 2 that displays significant under- 
expression, miR-133. Another ancient miRNA ${ }^{13}, \quad m i R-133$ is actually three miRNAs in the human genome; miR133a-1 on chromosome 18, miR-133a-2 on chromosome 20 , and miR-133b on chromosome 6 . The 22 nt mature miRNA of miR-133a-1 and miR-133a-2 is identical and miR-133b differs only in position 22 (GA). Moreover, miR133a-1, miR-133a-2, miR-133b are polycistronic with miR-1-2/miR-1-1/miR206 respectively, which themselves share nearly identical mature sequences, and this relationship was established as long ago as $6.7 \times 10^{8}$ years ago with the emergence of the bilateria. In fact, all of the miRNAs found in Table 2 are members of ancient miRNA lineages with most appearing well before the emergence of the Chordates $5 \times 10^{8}$ years ago (Table 3 ). This is not surprising, since cancer is a dramatic re-programming of basic cellular functions ${ }^{11}$ it stands to reason that deeply rooted, highly conserved miRNAs involved in regulating basic cellular functions would be preferentially affected.

Table 3. Evolutionary emergence of the miRNAs in Table 2. Taxon assignments are based upon detection of individual miRNAs in representative species reported in Sempere et al. ${ }^{13}$.

Taxon $\quad$ Emergence $(\text { Years })^{1} \quad$ microRNA

$\begin{array}{lll}\text { Eumetazoa } & 700,000,000 & m i R-10 \\ \text { Triploblastica } & 680,000,000 & m i R-31 \\ \text { Nephrozoa } & 670,000,000 & m i R-1, m i R-133, m i R-210 \\ \text { Deuterostomia } & 535,000,000 & m i R-141, m i R-183, m i R-200 \\ & & m i R-429 \\ \text { Chordata } & 500,000,000 & m i R-107 \\ \text { Osteichthyes } & 410,000,000 & m i R-106, m i R-155, m i R-182 \\ & & m i R-203, m i R-205\end{array}$

${ }^{1}$ Average of estimates based upon both paleontologic and molecular evidence provided primarily in Peterson et al. ${ }^{21}$.

The miRNA dysregulation signature of human endometrial cancer presented here, because it is deeply rooted in animal evolution, is likely part of a generic dysregulation signature in many human cancers. Most of these miRNAs are seen to be significantly dysregulated in other cancers as well including leukemia, ovary, lung, prostate, colorectal, brain, and pancreas ${ }^{22}$. It is certainly possible that these observations are statistical artifact since 
miRNAs with low miRBase archive numbers $^{23}$ are those that were first identified and have been included in various arrays for several years. On the other hand, these miRNAs continue to be represented even as the size and complexity of miRNA arrays has increased.

If there is a functional overrepresentation of the more ancient miRNAs in human cancers, adding to and overlaying this background are many miRNAs that appeared following the emergence of the land animals ${ }^{13}$. The human miRNAome retains the ancient miRNAs but also has hundreds of new miRNAs that are only found in mammals and more only found in primates or in hominids ${ }^{13}$. When seeking to derive a true miRNA signature of human endometrial cancers it is reasonable to expect that endometrialspecific miRNA expression patterns will be layered over the ancient, generic "cancer pattern" presented here. The task now is to identify these histologyspecific miRNAs, add them to the core miRNAs, and use them to develop diagnostic and prognostic assays as well as identify their mRNA and pathway targets.

\section{References}

1. Fabian MR, Sonenberg N, Filipowicz W. Regulation of mRNA translation and stability by microRNAs. Annu Rev Biochem. 2010;79:351-79.

2. Nana-Sinkam SP, Croce CM. MicroRNAs as therapeutic targets in cancer. Transl Res. 2011 Apr;157(4):216-25. Epub 2011 Feb 4.
3. Devor EJ, Hovey AM, Goodheart MJ, Ramachandran S, Leslie KK. microRNA expression profiling of endometrial endometrioid adenocarcinomas and serous adenocarcinomas reveals profiles containing shared, unique and differentiating groups of microRNAs. Oncol Rep. 2011 Oct;26(4):995-1002. doi:10.3892/or.2011.1372. Epub 2011 Jul 1

4. Devor EJ, DeMik JN, Ramachandran S, Goodheart MJ, Leslie KK. Global dysregulation of the chromosome $14 q 32$ imprinted region in uterine carcinosarcoma. In preparation 2011.

5. Boren $\mathrm{T}$, Xiong $\mathrm{Y}$, Hakam $\mathrm{A}$, Wenham R, Apte S, Wei Z, Kamath S, Chen DT, Dressman $\mathrm{H}$, Lancaster JM. MicroRNAs and their target messenger RNAs associated with endometrial carcinogenesis. Gynecol Oncol. 2008 Aug;110(2):206-15. Epu 2008 May 21.

6. Chung TK, Cheung TH, Huen NY, Wong KW, Lo KW, Yim SF, Siu NS, Wong YM, Tsang PT, Pang MW, Yu MY, To KF, Mok SC, Wang VW, Li C, Cheung AY, Doran G, Birrer MJ, Smith DI, Wong YF. Dysregulated microRNAs and their predicted targets associated with endometrioid endometrial adenocarcinoma in Hong Kong women. Int J Cancer. 2009 Mar 15;124(6):135865.

7. Wu W, Lin Z, Zhuang Z, Liang X. Expression profile of mammalian microRNAs in endometrioid adenocarcinoma. Eur J Cancer Prev. 2009 Feb;18(1):50-5.

8. Hiroki E, Akahira J, Suzuki F, Nagase $\mathrm{S}$, Ito K, Suzuki T, Sasano H, Yaegashi $\mathrm{N}$. Changes in microRNA expression levels correlate with clinicopathological features and prognoses in endometrial serous adenocarcinomas. Cancer Sci. 2010 Jan;101(1):241-9. Epub 2009 Oct 8. 
9. Ratner ES, Tuck D, Richter C, Nallur S, Patel RM, Schultz V, Hui P, Schwartz PE, Rutherford TJ, Weidhaas JB. MicroRNA signatures differentiate uterine cancer tumor subtypes. Gynecol Oncol. 2010 Sep;118(3):251-7. Epub 2010 Jun 9.

10. Cohn DE, Fabbri M, Valeri $\mathrm{N}$, Alder $\mathrm{H}$, Ivanov I, Liu CG, Croce CM, Resnick $\mathrm{KE}$. Comprehensive miRNA profiling of surgically staged endometrial cancer. Am J Obstet Gynecol. 2010 Jun;202(6):656.e1-8. Epub 2010 Apr 18.

11. Devor EJ. MicroRNAs, cellular behavior, and endometrial cancer. Proc Obstet Gynecol. 2010 Oct; 1(2): Article $1[15$ p.].

12. Spizzo R, Nicoloso MS, Croce CM, Calin GA. SnapShot: MicroRNAs in Cancer. Cell. 2009 May 1;137(3):586586.e1.

13. Sempere LF, Cole CN, McPeek MA, Peterson KJ. The phylogenetic distribution of metazoan microRNAs: insights into evolutionary complexity and constraint. J Exp Zool B Mol Dev Evol. 2006 Nov 15;306(6):575-88.

14. Wright JA, Richer JK, Goodall GJ. microRNAs and EMT in mammary cells and breast cancer. J Mammary Gland Biol Neoplasia. 2010 Jun;15(2):213-23. Epub 2010 May 25.

15. Cochrane DR, Spoelstra NS, Howe EN, Nordeen SK, Richer JK. MicroRNA200c mitigates invasiveness and restores sensitivity to microtubuletargeting chemotherapeutic agents. Mol Cancer Ther. 2009 May;8(5):1055-66. Epub 2009 May 12.

16. Gregory PA, Bert AG, Paterson EL, Barry SC, Tsykin A, Farshid G, Vadas MA, Khew-Goodall Y, Goodall GJ. The miR-200 family and miR-205 regulate epithelial to mesenchymal transition by targeting ZEB1 and SIP1. Nat Cell Biol.
2008 May;10(5):593-601. Epub 2008 Mar 30.

17. Castilla MÁ, Moreno-Bueno G, Romero-Pérez L, Van De Vijver $K$, Biscuola M, López-García MÁ, Prat J, Matías-Guiu X, Cano A, Oliva $E$, Palacios J. Micro RNA signature of the epithelial-mesenchymal transition in endometrial carcinosarcoma. J Pathol. 2011 Jan;223(1):72-80.

18. Thiery JP, Acloque $\mathrm{H}$, Huang RY, Nieto MA. Epithelial-mesenchymal transitions in development and disease. Cell. 2009 Nov 25;139(5):871-90.

19. Faraoni I, Antonetti FR, Cardone J, Bonmassar E. miR-155 gene: a typical multifunctional microRNA. Biochim Biophys Acta. 2009 Jun;1792(6):497505. Epub 2009 Mar 5.

20. Kulshreshtha $R$, Ferracin $M$, Wojcik SE, Garzon R, Alder H, Agosto-Perez FJ, Davuluri R, Liu CG, Croce CM, Negrini M, Calin GA, Ivan M. A microRNA signature of hypoxia. Mol Cell Biol. 2007 Mar;27(5):1859-67. Epub 2006 Dec 28.

21. Peterson KJ, Cotton JA, Gehling JG, Pisani D. The Ediacaran emergence of bilaterians: congruence between the genetic and the geological fossil records. Philos Trans R Soc Lond B Biol Sci. 2008 Apr 27;363(1496):1435-43.

22. Ferdin J, Kunej T, Calin GA. Noncoding RNAs: identification of cancerassociated microRNAs by gene profiling. Technol Cancer Res Treat. 2010 Apr;9(2):123-38.

23. Griffiths-Jones S, Saini HK, van Dongen S, Enright AJ. miRBase: tools for microRNA genomics. Nucleic Acids Res. 2008 Jan;36(Database issue):D154-8. Epub 2007 Nov 8. 